\title{
The Effect of Alignment Strategy on Organizational Performance in Jordanian Banks Registered in Amman Stock Exchange up to 2012
}

\author{
Mohannad Sami Hassan Tawaha ${ }^{1}$ \\ ${ }^{1}$ COB- Strategic Department, University Utara Malaysia, Malaysia \\ Correspondence: Dr. Mohannad Sami Hassan Tawaha, COB- Strategic Department, University Utara Malaysia, \\ Malaysia. E-mail: tawaha2001@yahoo.com
}

Received: April 24, 2015

Accepted: May 9, 2015

Online Published: May 14, 2015

doi:10.5430/ijba.v6n3p94

URL: http://dx.doi.org/10.5430/ijba.v6n3p94

\begin{abstract}
Strategic alignment is widely believed to improve company's performance. This study examines the impact of strategic alignment on perceived maturity alignment model. Empirical data from 15 banks in Jordan are analyzed. Results indicate a significant effect between the strategic alignment and organizational performance.
\end{abstract}

Keywords: business strategy, strategic alignment, organizational performance, maturity alignment model

\section{Background}

Organizations invest a large percentage of their resources in IT to improve the performance. However executives have frequently stated that they have not realized value from this investment(E. Oz, 2005). Past researchers have tried to find out the justification of spending this substantial amount of money. They found two different results, first: there is not excuse to spend these amounts of money to improve IT because there is no existence relationship between IT and performance (Kettinger, Grover, Guha, \& Segars, 1994; Nudurupati \& Bititci, 2005; Sharma, 2008). Second: there is impact of IT on performance (Farhanghi, Abbaspour, \& Ghassemi, 2013).

Since decades, researcher has attempted to intangible relationship between information technologies and organizational performance. The results uncovered a paradox in the relationship (Lee \& Barua, 1999). There is some evidence argued that IT investments can lead to profitability and productivity. However, one question remains unanswered: can IT be a strategic weapon, rather than just a productivity-enhancing tool for organization. And also have argued that IT is only an infrastructural commodity, it is needed just for organizational activities and operations, which mean it cannot provide strategic advantages (Venkatesh, Bala, Venkatraman, \& Bates, 2007). In contrast, others argue that IT capabilities can indeed be used to achieve strategic benefits. In other words there is a lack of knowledge about this issue (Aral \& Weill, 2007). And this paradox has been giving researchers an indicator may not be a direct relationship between IT and performance, but there is intermediated by other factors such as the alignment (Cragg, King, \& Hussin, 2002).

According to (Huang \& Qing, 2007) alignment is not just a process ,but a mindset of how IT can work for, and with, business all the time. Also some scholars found reasons why attaining IT-alignment has been so elusive, and they found the main reason is the definition of alignment focused only on how IT aligned with the business, and they assert the alignment must focus on how IT and the business are aligned with each other (Luftman \& Kempaiah, 2007). Many scholars call to examine the alignment because there is insufficient understanding of the relationship among contextual factors (Aral \& Weill, 2007; Huang \& Qing, 2007; Iman \& Hartono, 2007; Kearns \& Sabherwal, 2006; Sabberwal \& Chan, 2001; Paul P Tallon, 2011; Tanriverdi, 2005).

The alignment of IT and business strategy is a perennial challenge for corporate executives. While earlier studies confirm the value of alignment (Jorfi \& Jorfi, 2011), there is still some question as to how alignment creates value and the level at which value is created (Paul P Tallon, 2011). Based on the above, this study sought to measure the impact of the level of alignment strategies between the strategic orientation and information technology to enhancing organizational performance, and will support this idea through a review of some previous studies.

Managing performance of a corporation is a key factor that leads to stability and growth of any corporation. Recent studies indicate to the need for further studies in this area through linking between performance and other factors that could have an impact on it (Aral \& Weill, 2007; Botella, Peña, Contreras, Shih, \& Santacreu, 2009; Byrd, Pitts, Adrian, 
\& Davidson, 2008; Calderon, Seo, \& Kim, 2011). According to (Nakata, Zhen, \& Kraimer, 2008), despite the wide acceptance of computers, the contribution of IT capability to business performance is not entirely clear. Referring to the past studies in the performance field some of them were saying that there is paradox in their findings while they were examining the relationship between the IT, and the performance (Aral \& Weill, 2007; Cragg et al., 2002; Huang \& Qing, 2007; Paul P. Tallon, 2007; Velcu, 2010; Venkatesh et al., 2007).

On another hand, scholars have been examining the effect of strategies on performance, and they assert to re-examine the impact of strategies on other countries in order to find out differences and similarities among countries (Pleshko \& Nickerson, 2008). They indicate that there is a paradox in the findings of the relationship between the strategies and performance (Pleshko \& Nickerson, 2008), thus, they suggested to restudy this relationship (Dimitrios, Sakas, \& Vlachos, 2013).

Through the above, and based on what referred to some previous studies, which dealt with a whole the impact of information technology on performance measurement directly overlooked that this technology does not work alone within the organization, there are other sources of power has to be taken into account. Therefore, this study aims to examine the relationship between strategic alignments to improve company's performance in Jordanian banking sector which are registered in Amman Stock Exchange.

\section{Methods}

Depending on the problem of the study and the recommendations of some of the previous studies and objectives, this study attempts to answer the one question: What is the direct impact between strategic alignments on the corporates performance.

This study comes in response to the requirements of practical reality in the Jordanian banking sector, and in addition to the need for theory highlighted by previous studies; therefore can be summed objectives of the study the following points: Study actually applied for the strategic directions for information technology and the strategic directions of the organization used in the Jordanian banking sector. And Study the effect of alignment between the strategic direction of information technology trends and strategy of the organization used in the Jordanian banking sector strategies.

Confined to the field of study within the framework of the working structure of the study, which deals with both variables on the grounds that they are independent: strategic directions for the organization, strategic directions for information technology, and organizational performance variable, which is dependent variable, shows the practical study model.

This study was based on an inventory of all Jordanian banks listed on the Amman Stock Exchange until the end of 2012. It has been the adoption of the survey methodology through the design of a questionnaire distributed to the executive management staff of each bank as one of the units of the study sample. Represented the unit of analysis Managers Executives at the banks registered in Amman Stock Exchange, estimated at 183 Executive Director, The questionnaire was distributed to all registered banks, according to the number of executives who are in each bank, and has been distributed 183 questionnaire, and will return them 124 questionnaire and rate $66.7 \%$, and has been the exclusion of two questionnaires; for not disqualified because of the large gap in the answers to the paragraphs.

\section{Measures}

Strategic alignment: This refers to the combination or composition of organizational strategic characteristics used by organizations specifically referring to the study of the nature of the strategic orientations and the nature of information technology strategies which used in the organization. and to determine the level of harmonization strategy between these two variables in the Jordanian banking sector, through Maturity Model alignment strategies, it was introduced in 2000 by the researcher Loftman, which consists of six key components, from which assess the degree of maturity of the harmonization achieved in the organization, and these components are:

1. Communication: It is intended to measure the effectiveness of the exchange of ideas, knowledge and information between IT and business organizations.

2. Competitive and refers to the scale that determines the contribution of information technology and the organization of work in order to understand and accept each other.

3. Governance: and respect this component identifying the owner of power in the industry Resolution Information Technology, also identifies IT unauthorized operations and what is the scope of executives work with regard to determining dealing with strategies and plans at the operational level in the IT department mechanisms; in order to determine priorities and sources of information technology. 
4. Partnership: measures the relationship between works and organize information technology, and includes the role of information technology in the definition of business strategy, and the degree of trust between the two organizations, and how aware of each of others post the other party?

5. Scope and Architecture: This component serves to measure the degree of infrastructure for IT flexibility.

6. Skills: measure the human resources applications, such as operating, and maintaining, training, and feedback to measure the level of performance, and encourage creativity, and provide job opportunities, and the development of individual skills of workers, as ready organize and measure the change, and the ability to learn, and the ability to take advantage of new ideas (Khaiata \& Zualkernan, 2009).

Based on this previous six ingredients, strategic Alignment have been identified five levels of alignment between strategic technology and strategic orientation : first: the level of initial operations, II: promising level of operations, third: vehicle operations, and construction level, IV: Managed operations, and improved level, V: the level of process improvement (Luftman \& Kempaiah, 2007).

Organizational performance: this study adopted Bergeron definition, which refers to the organizational performance on the basis that the strength and ability of the Organization's strategic compared with competitors, can be divided into three dimensions:

1. profitability: can be measured using some financial indicators, such as return on investment, return on sales, and earnings per share, and this dimension respect to measuring the strength of the organization. I have been dealing with these different indicators in comparison with competitors.

2. Growth: In this dimension will be taking into account the time impact of the financial situation of the organization and its comparison with competitors using some indicators, such as: sales growth rate, and the percentage of profit growth. (Bergeron, Raymond, \& Rivard, 2004)

3. Competitive Advantage: adoption of the definition provided by the researchers (Lai, Zhao, \& Wang, 2007), which refers to the improved performance associated with key competitors in the same industry regulation, and have been certified divided into three dimensions: cost advantage, and the diversity of services and quality of services provided, compared with competitors.

\section{Hypotheses}

In response to by some previous studies in the recommendations referred to previously, in response to the need of practice in the Jordanian banking sector, have been identified hypotheses that will be addressed in this study out of her problem and objectives, which are based on the fundamental premise asserts there is the impact of significant strategic harmonization, We have emerged from this basic premise six hypotheses, which are as follows:

1. There is a significant statistically impact to level of Communications at the level of performance.

2. There is a significant statistically impact to level of Competitive at the level of performance.

3. There is a significant statistically impact to level of Governance at the level of performance.

4. There is a significant statistically impact to level of Partnership effect at the level of performance.

5. There is a significant statistically impact to level of the Scope and Architecture at the level of performance.

6. There is a significant statistically impact to level of skills at the level of performance.

\section{Measuring}

In this study, the measurement tool tests during the application of performance, both reliability model, namely: Believe phenomenon and sincerity content, were also measured the performance stability of the model study, consisting of 44 items have been prepared; for the purposes of the statement of the effect of aligning strategy, organizational performance, using a scale It is a Cronbach's Alpha. Below is a breakdown of these actions.

\section{First: reliability.}

1. Virtual reliability: It means that the paragraphs contained in this paper form based on variables measuring properly, and to this end has been the study form a group of specialists professors, were taking their recommendations and modify some of the paragraphs, and then display Form study on a group of managers in different departments to emphasize the clarity of the paragraphs of the form, to modification of some paragraphs. 
2. Content reliability: It uses this type of scales; to make sure that the number of items used to measure the appropriate variable, and accurately represents the variable to be measured, and has been confirmed the veracity of the content through the stages of development of the form, and as we mentioned earlier.

\section{Second: Stability:}

We have been using SPSS; to extract the internal consistency coefficient Cronbach's Alpha, paragraphs different study to make sure the stability of the measuring instrument, and we have found that the value of alpha for strategic alignment $71.5 \%$ and organizational performance 96.3 , and note that both values reached $60 \%$ or more, and this is an acceptable level of stability of internal consistency (Uma, 2000).

\section{Community and the study sample:}

The study population consisted of all workers in Jordanian banks registered in the Amman Stock Exchange until 2012, and there are 15 banks. Annual Report of the Securities 2012.Represented the unit of analysis Managers Executives in Jordanian banks registered in Amman exchange market, estimated at 183 executive director, and representatives of the (general manager of the bank(market, 2012), and his assistants, and managers of the various administrative units, and managers who are classified in the bank under the name of an executive director, and has been distributed form on all banks, according to the number of executives who are in each bank, and was distributed 183 questionnaire, and collected only 124 questionnaire, rate $67.8 \%$, and has been exclusion of two questionnaires; for not disqualified because of the large gap in the answer to paragraphs.

\section{Review of the Mean and the Standard Deviation of the Variables Head}

Will review the four independent variables branches separately, and then the dependent variable of the three branches.

Alignment: As shown in the Table 1; the mean value 3.20, the standard deviation 0.42 indicate the presence of a medium-sized alignment in the Jordanian banking sector, and this variable cycle is divided into six sub-variants, are:

1. Communications: As shown in the Table 1; the mean value 3.26 and standard deviation 0.21 , and this suggests that an understanding of the environment for both IT and business and are dealing with them appropriately, and communication between the various parties easy and affordable mechanisms; thus increasing the exchange of knowledge between the various parties.

2. Competitiveness: The Table 1 that the mean value 2.99 and standard deviation 0.71 refers to the competitive presence of medium strength, also shows that the contribution of each of the work and information technology are measured, and are also modify this metrics on a regular basis; a pen to process integration of these standards, and is working on the application of formal and informal standards.

3. Governance: The in Table 1 the mean value 3.01 and standard deviation 0.84 , which refers to the level of governance in the Jordanian banking sector, has been shown that the level of governance applied in the banking sector average power, show the presence of information technology strategic planning at the level of functional units process, and is dealing with the IT budget as an investment opportunity is designed to enable the organization to improve its performance, and show a margin of partnership between technology and work managers in committees devoted to improving organizational effectiveness.

4. Partnership: As shown in the Table 1; the mean value 3.49 and standard deviation 0.75 refers to the power of partnership between business units and information technology, it has been shown that all business units involved in the planning process Strategic information technology, as is the participation of the various departments in the direction and supervision of the IT process, with emphasis on the role of this technology in the strategic planning process to work, and take risks by enhancing the role of the partnership between the organization and IT.

5. Scope and Architecture: As shown in the Table 1; the mean value 3.48, the standard deviation 0.37, and indicate a high level of user technical level, it has been shown that the process of change is the goal of strengthening the systems used in the Jordanian banking sector, and that the different units in response to the technology standards are relatively high, showing that the architectural interrelated information technology at the level of the different business units, with an emphasis on the availability of appropriate infrastructure to support the process of organizational and technological change.

6. Skills: As the Table 1 the arithmetic mean value 2.96 and standard deviation 0.82 , which refers to the availability of medium strength basic skills, and show that the banking regulation supports the innovation process at the level of functional units and the level of organization, it turns out that the process will take a decision linked to the concept of force, shall be taken by the decisions at the senior management level with limited impact of information 
technology on this resolution, also shows that banking organizations adopt good programs provide staff training and skills appropriate to meet the change, as was emphasized the importance of identifying and training of staff the other functions in the organization.

Table 1. A table showing the mean and standard deviation of the variable alignment strategy

\begin{tabular}{ccc}
\hline Variables & S.D & Mean \\
\hline Communications & 0,21 & 3,26 \\
\hline Competitive & 0,71 & 2,99 \\
\hline Governance & 0,84 & 3,01 \\
\hline Partnership & 0,75 & 3,49 \\
\hline Scope and Architecture & 0.37 & 3,48 \\
\hline Alignment & 0,82 & 2,96 \\
\hline
\end{tabular}

Showing through the mean extraction of questions that assess alignment variable that the study sample responses for each bank individually indicate that the number of Jordanian banks, which has a standard alignment high is 3 banks $20 \%$ of the total subject to the process of measuring banks, showing that the number of banks that have a medium level of alignment is 12 Bank $20 \%$, and also shows that there is no banks where the low level of alignment, and this is shown in the Table 2.

Table 2. A table showing the level of alignment in Jordanian banks

\begin{tabular}{cccc}
\hline $\begin{array}{c}\text { Level of } \\
\text { alignment }\end{array}$ & ratio & $\begin{array}{c}\text { number of } \\
\text { banks }\end{array}$ & Main \\
\hline Low & $\% 20$ & 0 & Less than2,50 \\
\hline Medium & $\% 80$ & 12 & $3,50-2,50$ \\
\hline High & $\% 0$ & 3 & more than3,50 \\
\hline
\end{tabular}

Based on a combination of Alignment components have been identified five levels of Alignment between IT and work, and referred to previously. (Luftman \& Kempaiah, 2007). Thus, the study sample responses confirm that the majority of Jordanian banks in the $80 \%$ are located between the two levels of Alignment, namely: the level of construction and the level of managed operations, it means third level and fourth level. Organizational Performance: As shown in the Table 3; the mean value 3.08 and standard deviation 0.48 , indicating that the organizational performance in the Jordanian banking sector has average power, this variable is divided into three sub-variables are:

1. Profitability: As shown in the Table 3; the mean value is 2.82 and standard deviation 0.78 , and this indicates that some banking organizations have an average strength index with respect to profitability, it has been shown that return on average shareholders 'equity for the last two years, compared with competitors' average power, and the average return on investment compared to competitors average power, and the total financial performance point for that as well, and this requires a re-working to improve profitability in the banking sector.

2. Growth: The Table 3 shows mean value 3.04 and standard deviation 0.69 , which refers to the medium growth in the Jordanian banking sector in the last two years of the three ratios: market share, the size of investment, and the return on investment for the last two years.

3. Competitive advantage: as shown in Table 3 the value of mean 3.37 and standard deviation 0.40 , which indicates that the Jordanian banking sector has a competitive advantage medium strength, the study sample responses indicated a competitive price between banks, with an emphasis on competitive presence in providing a variety of services for customers to meet the needs of the market and enhance the market share of the bank. 
Table 3. A table showing the mean and standard deviation for performance

\begin{tabular}{ccc}
\hline variables & Mean & Standard deviation \\
\hline profitability & 2,82 &, 078 \\
\hline growth & 3,04 &, 69 \\
\hline $\begin{array}{c}\text { Competitive } \\
\text { advantages }\end{array}$ & 3,37 &, 40 \\
\hline performance & 3,08 &, 47 \\
\hline
\end{tabular}

\section{Hypothesis Testing and Analysis of the Results}

This study aimed to test the impact of strategic Alignment between strategic Information Technology and the organizational strategies on organizational performance in Jordanian banks registered in Amman Stock Exchange until 2012. The following is a review of the analysis of the hypotheses:

1. The first sub-hypothesis: There is a significant statistically impact to the level of communication at the level of performance. Show a negative and weak correlation, and it is statistically insignificant at $\alpha \leq 0.05$ between the level of communications and organizational performance; indicating to reject the hypothesis.

2. The second sub-hypothesis: There is a significant statistically impact to the level of Competitive at the level of performance. Show a weak positive correlation statistically significant at $\alpha \leq 0.05$ between the level of competitiveness and organizational performance; which refers to accept the hypothesis.

3. There is a significant statistically impact to the level of Governance on the level of performance. Show a positive and weak correlation, and it is statistically insignificant at $\alpha \leq 0.05$ between the level of Governance and organizational performance; indicating to reject the hypothesis.

4. There is a significant statistically impact to the level of partnership effect at the level of performance. Show a positive and medium correlation, and it is statistically insignificant at $\alpha \leq 0.05$ between the level of partnership and organizational performance; indicating to accept the hypothesis.

5. There is a significant statistically impact to the level of Scope and Architecture at the level of performance. Show a positive and weak correlation, and it is statistically insignificant at $\alpha \leq 0.05$ between the level of Scope and Architecture and organizational performance; indicating to accept the hypothesis.

6. There is a significant statistically impact to the level of skills on the level of performance. Show a weak positive correlation statistically significant at $\alpha \leq 0.05$ between the level of skills and organizational performance; which refers to reject the hypothesis.

Table 4. A table showing the correlation coefficient for variable levels of alignment

\begin{tabular}{|c|c|c|c|c|c|c|}
\hline variables & Significant & $\mathrm{T}$ & $\mathrm{B}$ & $\mathrm{R}$ & $\mathrm{F}$ & Significant \\
\hline communication & Insignificant & $0,97-$ & $0,07-$ & \multirow{6}{*}{0,23} & \multirow{6}{*}{6,72} & \multirow{6}{*}{ significant } \\
\hline competitive & Insignificant & $0,52-$ & $0,05-$ & & & \\
\hline governance & Insignificant & 0,11 & 0,02 & & & \\
\hline partnership & Significant & 7,17 & 0,55 & & & \\
\hline Scope and Architecture & Significant & 3,08 & 0,24 & & & \\
\hline skills & Insignificant & 0,45 & 0,04 & & & \\
\hline
\end{tabular}

Table 4 shows a positive and weak correlation, and it is statistically significant at $\alpha \leq 0.05$ between the strategic alignment and organizational performance; indicating to accept the hypothesis. This result is similar to the findings of some researchers. (Sabherwal \& Chan, 2001)

\section{Conclusion}

With regard to the level of alignment in the Jordanian banking regulation, it has been shown that twelve banks $80 \%$ reached the highest level of alignment, in contrast, gust three banks $20 \%$ reached to medium alignment, and no banks with lowest alignment. 
About the effect of alignment we found a positive and weak correlation, and it is statistically significant at $\alpha \leq 0.05$ between the strategic alignment and organizational performance; indicating to accept the hypothesis. (Sabherwal \& Chan, 2001)

We found at communication level a strong understanding of the environment for both IT and business and are dealing with them appropriately, and communication between the various parties easy and affordable mechanisms; thus increasing the exchange of knowledge between the various parties. And we found a medium strength in competitive presence, also shows that the contribution of each of the work and information technology are measured, and are also modify this metrics on a regular basis; a pen to process integration of these standards, and is working on the application of formal and informal standards. the level of governance applied in the banking sector average power, shows the presence of information technology strategic planning at the level of functional units process, and is dealing with the IT budget as an investment opportunity, and it is designed to enable the organization to improve its performance, about partnership we notes relation between technology and work managers in committees devoted to improving organizational effectiveness. partnership between business units and information technology, it has been shown that all business units involved in the planning process Strategic information technology, as well as the participation of the various departments in the direction and supervision of the IT process. Scope and Architecture it has been shown that the process of change is the goal of strengthening the systems used in the Jordanian banking sector, and that the different units in response to the technology standards are relatively high, showing that the architectural interrelated information technology at the level of the different business units, with an emphasis on the availability of appropriate infrastructure to support the process of organizational and technological change. A skill, shows in banking regulation supports the innovation process at the level of functional units and the level of organization. It turns out that the process will take a decision linked to the concept of force, shall be taken by the decisions at the senior management level with limited impact of information technology on this resolution, also shows that banking organizations adopt good programs provide staff training and skills appropriate to meet the change, as was emphasized the importance of identifying and training of staff the other functions in the organization.

On the other hand profitability has been shown that return on average shareholders 'equity for the last two years, compared with competitors is medium power, and the average return on investment compared to competitor's medium power, and the total financial performance point for that as well, and this requires a re-working to improve profitability in the banking sector. And we found medium growth in the Jordanian banking sector in the last two years of the three ratios market share, the size of investment, and the return on investment for the last two years. Also, found medium strength in competitive advantage, the study sample responses indicated a competitive price between banks, with an emphasis on competitive presence in providing a variety of services for customers to meet the needs of the market and enhance the market share of the bank.

\section{References}

Aral, S., \& Weill, P. (2007). IT assets, organizational capabilities, and firm performance: How resource allocations and organizational differences explain performance variation. Organization Science, 18(5), 763-780. http://dx.doi.org/10.1287/orsc.1070.0306

Bergeron, F., Raymond, L., \& Rivard, S. (2004). Ideal patterns of strategic alignment and business performance. Information \& management, 41(8), 1003-1020. http://dx.doi.org/10.1016/j.im.2003.10.004

Botella, J., Peña, D., Contreras, M.a.J., Shih, P.C., \& Santacreu, J. (2009). Performance as a Function of Ability, Resources Invested, and Strategy Used. Journal of General Psychology, 136(1), 41-70.

Byrd, T.A., Pitts, J.P., Adrian, A.M., \& Davidson, N.W. (2008). Examination of a Path Model Relating Information Technology Infrastructure with Firm Performance. Journal of Business Logistics, 29(2), 161-187.

Calderon, T.G., Seo, S., \& Kim, I.W. (2011). Information technology and the performance of financial companies in South Korea. Journal of Applied Business Research (JABR), 17(2).

Cragg, P., King, M., \& Hussin, H. (2002). IT alignment and firm performance in small manufacturing firms. The Journal of Strategic Information Systems, 11(2), 109-132. http://dx.doi.org/10.1016/S0963-8687(02)00007-0

Dimitrios, N.K., Sakas, D.P., \& Vlachos, D. (2013). The Role of Information Systems in Creating Strategic Leadership Model. Procedia-Social and Behavioral Sciences, 73, 285-293.

Farhanghi, A.A., Abbaspour, A., \& Ghassemi, R.A. (2013). The effect of information technology on organizational structure and firm performance: An analysis of consultant engineers firms (CEF) in Iran. Procedia-Social and Behavioral Sciences, 81, 644-649. http://dx.doi.org/10.1016/j.sbspro.2013.06.490 
Huang, C.D., \& Qing, H. (2007). Achieving IT-Business Strategic Alignment via Enterprise-Wide Implementation of Balanced Scorecards. Information Systems Management, 24(2), 173-184.

Iman, N., \& Hartono, J. (2007). Strategic Alignment Impacts on Organizational Performance in Indonesian Banking Industry. Gadjah Mada International Journal of Business, 9(2), 253-272.

Jorfi, S., \& Jorfi, H. (2011). Strategic operations management: Investigating the factors impacting IT-business strategic alignment. Procedia-Social and Behavioral Sciences, 24, 1606-1614.

Kearns, G.S., \& Sabherwal, R. (2006). Strategic Alignment Between Business and Information Technology: A Knowledge-Based View of Behaviors, Outcome, and Consequences. Journal of Management Information Systems, 23(3), 129-162. http://dx.doi.org/10.2753/MIS0742-1222230306

Kettinger, W.J., Grover, V., Guha, S., \& Segars, A.H. (1994). Strategic Information Systems Revisited: A Study in Sustainability and Performance. MIS Quarterly, 18(1), 31-58. http://dx.doi.org/10.2307/249609

Khaiata, M., \& Zualkernan, I.A. (2009). A simple instrument to measure IT-business alignment maturity. Information Systems Management, 26(2), 138-152. http://dx.doi.org/10.1080/10580530902797524

Lai, F., Zhao, X., \& Wang, Q. (2007). Taxonomy of information technology strategy and its impact on the performance of third-party logistics (3PL) in China. International Journal of Production Research, 45(10), 2195-2218. http://dx.doi.org/10.1080/00207540600693531

Lee, B., \& Barua, A. (1999). An Integrated Assessment of Productivity and Efficiency Impacts of Information Technology Investments: Old Data, New Analysis and Evidence. Journal of Productivity Analysis, 12(1), 21-43. http://dx.doi.org/10.1023/A:1007898906629

Luftman, J., \& Kempaiah, R. (2007). An update on business-IT alignment:"A line” has been drawn. MIS Quarterly Executive, 6(3), 165-177.

Market, A.E. (2012). Annual Report of the Jordanian banks registered Retrieved July 24, 2011, from http://www.ase.com.jo/en/node/536

Nakata, C., Zhen, Z., \& Kraimer, M.L. (2008). The Complex Contribution of Information Technology Capability to Business Performance. Journal of Managerial Issues, 20(4), 485-506.

Nudurupati, S.S., \& Bititci, U.S. (2005). Implementation and impact of IT-supported performance measurement systems. Production Planning \& Control, 16(2), 152-162. http://dx.doi.org/10.1080/09537280512331333057

Oz, E. (2005). Information technology productivity: in search of a definite observation. Information \& Management, 42(6), 789-798. http://dx.doi.org/10.1016/j.im.2004.08.003

Pleshko, L., \& Nickerson, I. (2008). Strategic orientation, organizational structure, and the associated effects on performance in industrial firms. Academy of Strategic Management Journal, 7, 95.

Sabberwal, R., \& Chan, Y.E. (2001). Alignment between Business and IS Strategies: A Study of Prospectors, Analyzers, and Defenders. Information Systems Research, 12(1), 11-33.

Sharma, B. (2008). Technology Strategy, Contextual Factors and Business Performance: An Investigation of Their Relationship. South Asian Journal of Management, 15(3), 19-39.

Tallon, P.P. (2007). A Process-Oriented Perspective on the Alignment of Information Technology and Business Strategy. Journal of Management Information Systems, 24(3), 227-268.

Tallon, P.P. (2011). Value chain linkages and the spillover effects of strategic information technology alignment: A process-level view. Journal of Management Information Systems, 28(3), 9-44. http://dx.doi.org/10.2753/MIS0742-1222280301

Tanriverdi, H.S. (2005). Information Technology Relatedness Knowledge Management Capability, and Performance of Multibusiness Firms. MIS Quarterly, 29(2), 311-334.

Uma, S. (2000). Research methods for business: A skill-building approach. John Willey \& Sons, lnc. New York.

Velcu, O. (2010). Strategic alignment of ERP implementation stages: An empirical investigation. Information \& Management, 47(3), 158-166. http://dx.doi.org/10.1016/j.im.2010.01.005

Venkatesh, V., Bala, H., Venkatraman, S., \& Bates, J. (2007). Enterprise architecture maturity: the story of the veterans health administration. MIS Quarterly Executive, 6(2), 79-90. 